\title{
Two-phase reaction model of a gas-aluminum particles mixture detonation
}

\author{
Junzheng Yue, Hefei Dong \& Tao Hong
}

To cite this article: Junzheng Yue, Hefei Dong \& Tao Hong (2020): Two-phase reaction model of a gas-aluminum particles mixture detonation, Journal of Energetic Materials, DOI: 10.1080/07370652.2020.1727996

To link to this article: https://doi.org/10.1080/07370652.2020.1727996

\section{Published online: 17 Feb 2020.}

Submit your article to this journal ए]

\section{Џ Article views: 13}

Q View related articles $\sqsubset$

View Crossmark data ¿ 


\title{
Two-phase reaction model of a gas-aluminum particles mixture detonation
}

\author{
Junzheng Yue ${ }^{\mathrm{a}, \mathrm{b}}$, Hefei Dong ${ }^{\mathrm{a}}$, and Tao Hong ${ }^{\mathrm{a}}$ \\ anstitute of Applied Physics and Computational Mathematics, Beijing, China; 'bnstitute of Mechanics, Chinese \\ Academy of Science, Beijing, China
}

\begin{abstract}
The reaction model of aluminum particles is the key to successfully simulate the two-phase detonation of aluminum suspensions. In this study, by considering the decomposition of the aluminum oxide $\left(\mathrm{Al}_{2} \mathrm{O}_{3}\right)$ product at high temperature, the reaction model for aluminum particles is improved and is incorporated into the numerical code. Then numerical simulations for twophase detonations of $\mathrm{Al} / \mathrm{air}$ mixtures and $\mathrm{Al} / \mathrm{O}_{2}$ mixtures are performed, respectively, the simulated results for the peak pressure and the speed of the two-phase detonation wave are in agreement with the experimental results, which demonstrate the validity of the improved aluminum reaction model. Moreover, the detonation parameters and the distributions of the physical quantities around the detonation wave are analyzed.
\end{abstract}

\section{KEYWORDS}

Aluminum particles; reaction model; two-phase detonation; reverse reaction

\section{Introduction}

As one kind of industrial material used in common, aluminum particles are easily mixed with the air and lead to two-phase detonation during their production period, which can cause enormous damage (Liu and Zhang 2015). Besides, due to their high energy content, aluminum particles are usually added to solid rocket propellants and explosives. Considering the industrial safety and the application, the two-phase detonation involving aluminum suspensions has been extensively studied for many years (Fedorov and Khmel 2005; Veyssiere, Khasainov, and Briand 2008). Observation of the steady self-sustained detonation propagation in aluminum suspensions is difficult, and performing experiments in well-controlled and reproducible initial conditions of mixture composition remains problematic. Therefore, numerical simulation becomes a convenient way for the detonation study.

The major difficulty arising in numerical study for two-phase detonation of aluminum suspensions in oxidizing atmosphere is the modeling of aluminum combustion. In general, the combustion of Al particle is modeled as diffusion- or kinetics-limited regime. In the diffusion-limited regime, the chemical kinetic rate is fast, and the oxidizer diffusion rate is the limiting rate (Beckstead 2005), while in the kinetics-limited regime, the oxidizer diffusion to the $\mathrm{Al}$ particle surface is much faster, thus the chemical kinetics at the surface of the Al particle becomes the rate limiter (Bazyn, Krier, and Glumac 2007; Tanguay et al. 2009). Glorian et al. have theoretically investigated the role of surface kinetics and gas-phase mechanism regarding the particle size and the atmosphere (Glorian, Gallier, and Catoire 2016). In a previous simulation work, Khasainov et al. proposed a two-step model (Veyssiere, Khasainov, and Briand 2008), for which they adjusted kinetic parameters to ensure agreement with the available experimental data. Zhang et al. had proposed a hybrid model (Zhang, Gerrard, and Ripley 2009) that accounts for both the diffusion- and kinetics-limited regimes, they also discussed the conditions that determine the combustion regime. Similarly, Briand et al. improved their two-step model and developed a hybrid model too (Briand, Veyssiere, and Khasainov 2010). Whereas, 
there is a pre-exponential factor $Z_{\mathrm{hyb}}$ requiring fitting in these models, and there is no general consensus for $Z_{\text {hyb }}$ in the research community (Balakrishnan 2014); thus, it increases the difficulty of using these models.

In the present study, by considering the decomposition of the aluminum oxide $\left(\mathrm{Al}_{2} \mathrm{O}_{3}\right)$ product at high temperature, the diffusion reaction model is improved. Moreover, the improved reaction model of $\mathrm{Al}$ particles is incorporated into the homemade numerical code, which solves the two-phase flow equations with the space-time conservation element and solution element (CE/SE) method. Afterward, three-dimensional numerical simulations for two-phase detonations involving aluminum suspensions in air and pure oxygen atmospheres are performed, respectively; then, the simulation results are analyzed and are compared with the experimental results.

\section{Numerical Modeling}

\section{Hypothesis of Physical and Chemical Models}

As the two-phase detonation of aluminum suspensions is a complex physical and chemical process, we expound the gas-solid two-phase flow based on the following hypotheses (Kwon et al. 2003):

(1) Assume the aluminum particles to be incompressible and be dispersed uniformly in the gas.

(2) Assume the aluminum particles to be spherical and epigranular, the flake particle is equivalent to spherical particle and the equivalent method is elucidated in the following text.

(3) There are no temperature gradients or pressure inside the aluminum particles, ignore the action of gravity, interactions among the particles, as well as the energy loss caused by radiation.

(4) The energy released by the combustion of the $\mathrm{Al}$ particles is all absorbed by the gas.

\section{Governing Equations}

The two-phase flow model (Nigmatulin 1970) is adopted to describe the evolution of the $\mathrm{Al}$ suspensions detonation. The model assumes the gaseous and solid phases to be continuous media and takes into account the inter-phase exchange of mass, momentum, and energy. The balance equations for the two phases are as follows:

Gaseous phase:

$$
\begin{gathered}
\frac{\partial \rho_{1} \varphi_{1}}{\partial t}+\nabla \cdot\left(\rho_{1} \varphi_{1} \mathbf{u}\right)=I \\
\frac{\partial \rho_{1} \varphi_{1} \mathbf{u}}{\partial t}+\nabla \cdot\left(\left(\rho_{1} \varphi_{1} \mathbf{u}\right) \otimes \mathbf{u}\right)+\nabla p=I \mathbf{v}-\mathbf{F} \\
\frac{\partial \rho_{1} \varphi_{1}\left(e_{1}+\frac{1}{2} \mathbf{u} \cdot \mathbf{u}\right)}{\partial t}+\nabla \cdot\left(\varphi_{1} \mathbf{u}\left(\rho_{1}\left(e_{1}+\frac{1}{2} \mathbf{u} \cdot \mathbf{u}\right)+p\right)\right)=-Q+I\left(e_{2}+\frac{1}{2} \mathbf{v} \cdot \mathbf{v}+q_{A l}\right)-\mathbf{F} \cdot \mathbf{v}
\end{gathered}
$$

Solid phase:

$$
\begin{aligned}
\frac{\partial \rho_{2} \varphi_{2}}{\partial t}+\nabla \cdot\left(\rho_{2} \varphi_{2} \mathbf{v}\right) & =-I \\
\frac{\partial \rho_{2} \varphi_{2} \mathbf{v}}{\partial t}+\nabla \cdot\left(\left(\rho_{2} \varphi_{2} \mathbf{v}\right) \otimes \mathbf{v}\right) & =-I \mathbf{v}+\mathbf{F} \\
\frac{\partial \rho_{2} \varphi_{2}\left(e_{2}+\frac{1}{2} \mathbf{v} \cdot \mathbf{v}\right)}{\partial t}+\nabla \cdot\left(\rho_{2} \varphi_{2} \mathbf{v}\left(e_{2}+\frac{1}{2} \mathbf{v} \cdot \mathbf{v}\right)\right) & =Q-I\left(e_{2}+\frac{1}{2} \mathbf{v} \cdot \mathbf{v}\right)+\mathbf{F} \cdot \mathbf{v}
\end{aligned}
$$

Particle number balance equation:

$$
\frac{\partial n}{\partial t}+\nabla \cdot(n \mathbf{v})=0
$$

Gas species equation:

$$
\frac{\partial \rho_{1} \varphi_{1} y_{j}}{\partial t}+\nabla \cdot\left(\rho_{1} \varphi_{1} y_{j} \mathbf{u}\right)=\omega_{j}
$$




\section{Equation of state for the gas:}

$$
p=\rho_{1} R_{g a s} T_{1} \sum_{1}^{m} \frac{y_{j}}{w_{j}}
$$

\section{Specific internal energy for the two phases:}

$$
e_{1}=\int c_{v 1} d T_{1} ; e_{2}=c_{v 2} T_{2}
$$

where

subscripts 1 and 2: refer to the gaseous phase and the aluminum particles, respectively

$\rho$ : density

$T:$ temperature

$\mathbf{u , v}$ : velocity of the gas and the aluminum particles, respectively, the bold variables represent vectors

$c_{v 1}$ : specific heat capacity of the gas at constant volume, and it is a step function of gas temperature $T_{1}$ (Haynes 2014)

$c_{v 2}$ : specific heat capacity of aluminum, and the equation for $e_{2}$ already considers the phase transition

$p$ : gas pressure

$\varphi$ : volume fraction, and $\varphi_{1}+\varphi_{2}=1$

I: mass decrease rate of aluminum particles per unit volume

$q_{A l}:$ released energy per unit mass of aluminum

$n$ : aluminum particle number per unit volume

$y_{j}$ : mass fraction of the $j$ th species in the gas

$\omega_{j}$ : mass increase rate of the $j$ th gas species per unit volume

$R_{\text {gas }}:$ the universal gas constant

$w_{j}$ : molar mass of the $j$ th gas species

$\mathbf{F}$ is the drag force obtained from the gas for the particles, and is given by (Nigmatulin 1970):

$$
\mathbf{F}=\frac{1}{2} n \pi R^{2} C_{d} \rho_{1}|\mathbf{u}-\mathbf{v}|(\mathbf{u}-\mathbf{v})
$$

where $R$ is the radius of the aluminum particle, $C_{d}$ is the drag coefficient and is given by

$$
C_{d}=\left\{\begin{array}{cc}
\frac{24}{R e}\left(1+\frac{1}{6} R e^{2 / 3}\right) & R e<1000 \\
0.44 & R e \geq 1000
\end{array}\right.
$$

where $R e$ is the Reynolds number, and $R e=2 \rho_{1}|\mathbf{u}-\mathbf{v}| R / \mu$, in which $\mu$ is the gas viscosity.

The heat exchange rate $Q$ between the gas and the particles is (Nigmatulin 1970):

$$
Q=4 n \pi R^{2} \beta \lambda_{1} N u\left(T_{1}-T_{2}\right) /(2 R)
$$

where $\lambda_{1}$ is the thermal conductive coefficient of the gas, $N u$ is the Nusselt number, and $N u=2+0.459 \operatorname{Re}^{0.55} \operatorname{Pr}^{0.33}$, in which $\operatorname{Pr}$ is the Prandtl number and is determined as $\operatorname{Pr}=\mu c_{p} / \lambda_{1}$, where $c_{p}$ is the specific heat capacity of the gas at constant pressure.

The factor $\beta$ in Equation (13) is for the flake aluminum particle. In the present study, the flake particle is equivalent to the spherical particle with the equal mass, and $\beta$ is given by

$$
\beta=\left\{\begin{array}{cc}
S_{f} / S_{s} & T_{2} \leq T_{m} \\
1 & T_{2}>T_{m}
\end{array}\right.
$$

where $S_{f}$ is the real surface area of the flake particle, $S_{s}$ is the surface area of the equivalent spherical particle, $T_{m}$ is the melting temperature of aluminum. 
The reason why the factor $\beta$ is introduced into Equation (13) for the flake particle is that $S_{f}$ is bigger than $S_{s}$, which results that the flake particle can absorb more heat than the equivalent spherical particle in the high temperature flow during its melting period. After the flake aluminum particle melts into the liquid state, as the liquid aluminum drop is spherical, the factor $\beta$ equals to 1 . It should be noted that there is no factor $\beta$ in Equation (13) for the spherical aluminum particle, one can also say $\beta$ always equals to 1 for the spherical aluminum particle.

\section{Reaction Model}

The reaction model of aluminum particles is the innovation part of this paper. We previously used two-step model, which separates the induction and combustion periods, to describe the reaction process of the aluminum particles in two-phase detonation. For the induction period, considering the effect of the alumina shell, theoretical explanation for the ignition of aluminum particle at temperatures by Levitas et al. (Levitas et al. 2009) corresponds to the aluminum melting point. By investigating the mechanism of shock wave ignition of aluminum particle, Hong et al. (Hong and Qin 2003) also defined the melting temperature as the ignition temperature for aluminum particle under dynamic conditions. Therefore, we assume that the aluminum particle begins to react when it melts into the liquid state completely. For the combustion period, the reaction of aluminum particle is simplified as: $4 \mathrm{Al}+3 \mathrm{O}_{2} \rightarrow 2 \mathrm{Al}_{2} \mathrm{O}_{3}$, and the burning rate $\mathrm{I}$ is given by the diffusion reaction model (Price 1984):

$$
\begin{aligned}
I & =-n \rho_{2} 4 \pi R^{2} \frac{d R}{d t} \\
\frac{1}{R} \frac{d R}{d t} & =-\frac{1}{k d_{0}^{m} / \psi^{0.9}}
\end{aligned}
$$

where

$\rho_{2}$ : aluminum density

$R:$ radius of the aluminum particle, and it can be derived that $4 \mathrm{Al}+3 \mathrm{O}_{2} \rightarrow 2 \mathrm{Al}_{2} \mathrm{O}_{3}$

$d_{0}$ : initial mean diameter of the aluminum particles

$\psi$ : mole fraction of the oxygen in the gas

and $m=1.75, k=230850$ (Price 1984). Although the product $\mathrm{Al}_{2} \mathrm{O}_{3}$ is in the liquid state, it is assumed to be present in the form of very fine drops that behave as the gas phase; thus, it is treated as a gas component but has no contribution to the gas pressure (Kwon et al. 2003).

In the present study, the above two-step model is improved by introducing the decomposition reaction of the product $\mathrm{Al}_{2} \mathrm{O}_{3}$. As metal oxide generally does not exist in gaseous state (Steinberg, Wilson, and Benz 1992), the $\mathrm{Al}_{2} \mathrm{O}_{3}$ will decompose instantly once the temperature exceeds its boiling point. Similarly, the reverse reaction is simplified as: $2 \mathrm{Al}_{2} \mathrm{O}_{3} \rightarrow 4 \mathrm{Al}+3 \mathrm{O}_{2}$, this endothermic reaction will limit the maximum gas temperature, which was observed in the case of aluminum combustion (Glassman 1993). The boiling temperature $T_{\mathrm{b}}$ of $\mathrm{Al}_{2} \mathrm{O}_{3}$ is given by the Clapeyron equation (Shen and Tong 2007):

$$
\frac{1}{p} \frac{d p}{d T_{b}}=\frac{L v}{R_{g a s} T_{b}^{2}}
$$

where $p$ is the gas pressure, $L v$ is the latent heat of vaporization for $\mathrm{Al}_{2} \mathrm{O}_{3}$. For the detonation of $\mathrm{Al}$ particles/air mixtures, it is assumed that there are four kinds of gas species in the detonation flow field: $\mathrm{O}_{2}, \mathrm{~N}_{2}, \mathrm{Al}$, and $\mathrm{Al}_{2} \mathrm{O}_{3}$, while for the detonation of $\mathrm{Al}$ particles/pure oxygen mixtures, there is no $\mathrm{N}_{2}$ component. The values of main parameters used in the computational model are listed in Table 1.

The system of 3D equations (1-16) is solved in Cartesian $x-y-z$ coordinates using an Eulerian grid, the homemade numerical simulation program uses an explicit finite difference scheme based on the 
Table 1. Parameters for numerical simulation.

\begin{tabular}{lc}
\hline Parameter & Value \\
\hline Al density, $\rho_{2}\left(\mathrm{~kg} / \mathrm{m}^{3}\right)$ & 2700 \\
Melting temperature of $\mathrm{Al}, T_{m}(\mathrm{~K})$ & 931 \\
Specific heat capacity of $\mathrm{Al}, c_{v 2}(\mathrm{~J} /(\mathrm{kg} \cdot \mathrm{K}))$ & 905 \\
Released energy per unit mass of $\mathrm{Al}, q_{A l}(\mathrm{~J} / \mathrm{kg})$ & $3.15 \times 10^{7}$ \\
Latent heat of vaporization for $\mathrm{Al}_{2} \mathrm{O}_{3}, \mathrm{Lv}(\mathrm{J} / \mathrm{kg})$ & $4.77 \times 10^{6}$ \\
\hline
\end{tabular}

CE/SE method, and the fourth order Runge-Kutta method is used to solve the source terms of the governing equations. In addition, the stability is assured by the Courant-Friedrichs-Lewy (CFL) criterion.

\section{Verification of the Numerical Method}

To demonstrate the reliability of the numerical simulation program, simulations for SOD problem have been performed by different grids, and the simulation results are compared with the theoretical results. Moreover, the grid resolution is further demonstrated by $3 \mathrm{D}$ simulations for the $\mathrm{Al} / \mathrm{air}$ mixtures two-phase detonation.

\section{SOD Problem}

Two different grids, a coarse grid size of $2 \mathrm{~mm}$ and a refined grid size of $1 \mathrm{~mm}$, are adopted to simulate the shock tube problem which has the exact theoretical solution (Toro 2009) respectively. A tube with a size of $1 \mathrm{~m} \times 0.1 \mathrm{~m} \times 0.1 \mathrm{~m}$ is filled with the ideal gas, and there is a diaphragm at $x=0.5 \mathrm{~m}$ separating the gas to two parts, the initial states of the two parts of the gas are

$$
\left(\rho, u_{x}, u_{y}, u_{z}, p\right)=\left\{\begin{array}{cc}
\left(10 \mathrm{~kg} / \mathrm{m}^{3}, 0,0,0,1 \mathrm{MPa}\right) & 0 \leq x \leq 0.5 \mathrm{~m} \\
\left(1.25 \mathrm{~kg} / \mathrm{m}^{3}, 0,0,0,0.1 \mathrm{MPa}\right) & 0.5 \mathrm{~m}<x \leq 1 \mathrm{~m}
\end{array}\right.
$$

Simulation starts at the time when the diaphragm bursts; then, two parts of the gas begin to mix. Figure 1 shows the distributions of the gas density and the gas pressure at the same moment by simulations and theory, respectively. It appears that the simulation results by two different grids are both in good agreement with the theoretical results, indicating that the grid size at the range of $1 \sim 2 \mathrm{~mm}$ is suitable for simulation. The results confirm the reliability of the numerical method.
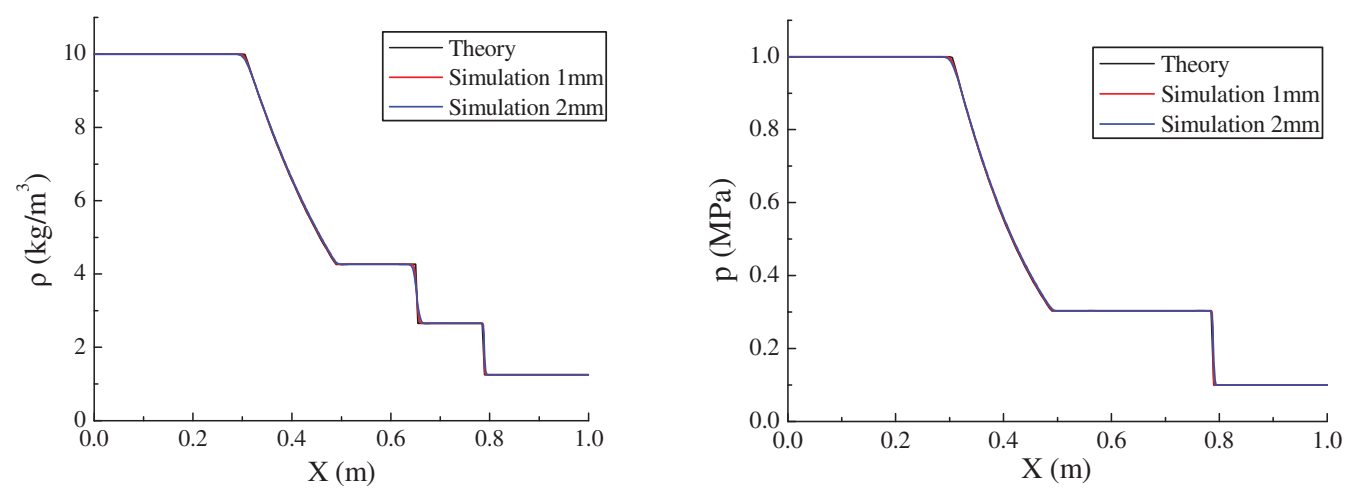

Figure 1. Comparison of simulated and theoretical distributions for gas density and gas pressure. 

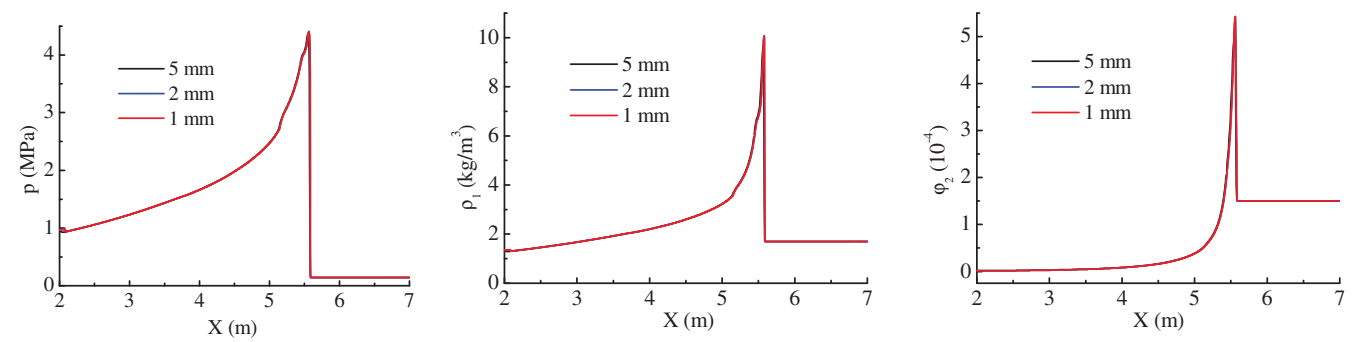

Figure 2. Simulated distributions for gas pressure, gas density, and Al volume fraction at $t=4 \mathrm{~ms}$ by different grids.

\section{Two-phase Detonation}

In order to validate the grid size for the two-phase detonation problem, three different grids: $1 \mathrm{~mm}$, $2 \mathrm{~mm}$, and $5 \mathrm{~mm}$ are used to perform the 3D simulation, respectively, for the Al/air mixtures detonation (the case is same to that in the following Section Al/air mixtures detonation). The simulation results for the distributions of the gas pressure, gas density, and the Al volume fraction at $t=4 \mathrm{~ms}$ by the three different grids are shown in Figure 2. It appears that the simulation results by the three different grids are in good agreement, despite the $5 \mathrm{~mm}$ grid simulates a slightly wider wavefront. The simulation results for the two-phase reactive flow confirm the grid resolution.

\section{Simulation Results and Analysis}

To verify the improved reaction model of aluminum particles, 3D simulation for $\mathrm{Al} /$ air mixtures detonation is performed. For explaining the improvement of the new model, the simulation for the $\mathrm{Al} /$ air mixtures detonation with the previous model is also carried out for comparison. Besides, in order to test the validity of the improved reaction model for different oxidizing atmosphere, the numerical simulation for the detonation of $\mathrm{Al}$ particles/pure oxygen mixtures is performed.

\section{Al/air Mixtures Detonation}

The detonation of flake $\mathrm{Al}$ particles/air mixtures in tube is considered based on the experiment carried out by Li et al. (Li 2017). According to the experiment, the flake Al particles with the average size of $15 \mu \mathrm{m} \times 12 \mu \mathrm{m} \times 0.8 \mu \mathrm{m}$ were dispersed uniformly in the detonation tube with the diameter of $0.199 \mathrm{~m}$, due to the $90 \%$ efficiency of dispersion, the concentration of the Al particles $\sigma_{2}$ is $405 \mathrm{~g} / \mathrm{m}^{3}$.

Considering that the detonation tube is axisymmetric, a quarter of the flow field is chosen as the computational domain. Figure 3(a) displays the transverse cross-section of the computational domain $(99.5 \mathrm{~mm} \times 99.5 \mathrm{~mm}), 81$ grid nodes are used in both the $Y$ and $Z$ directions, which means that the mesh interval is $1.244 \mathrm{~mm}$. In the Cartesian frame, the tube wall is approximately processed and is composed of horizontal and vertical elements. The length of the computational domain is $14 \mathrm{~m}$, and the mesh interval is $1.25 \mathrm{~mm}$, namely, 11201 grid nodes are used in the $X$ direction. In order to improve the computational efficiency and reduce cost, the grid nodes outside the tube wall, which are displayed by pale part in Figure 3(a), will not participate in the calculation. The total number of the grid node in the simulation run is more than 60 million; therefore, the numerical simulation is performed on 224 processors with a parallelization based on the MPI technique. The length of the tube is divided into 224 segments, and each of the processors calculates a $0.0625 \mathrm{~m}$ long part of the domain. There are 14 monitoring points positioned on the tube wall every $1 \mathrm{~m}$ along the $X$ direction recording the pressure histories.

The boundary conditions at the tube wall and the left closed wall of the detonation tube correspond to the rigid wall, and the boundary condition at the right end of the tube is flow out. 


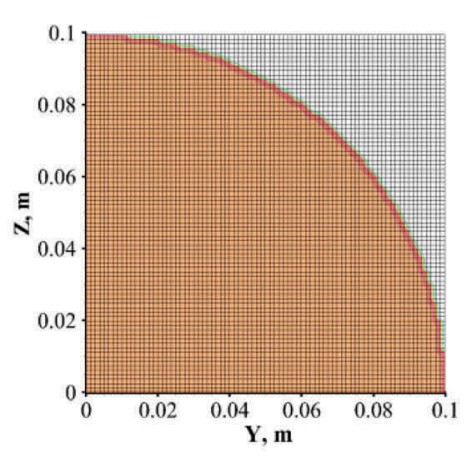

(a)

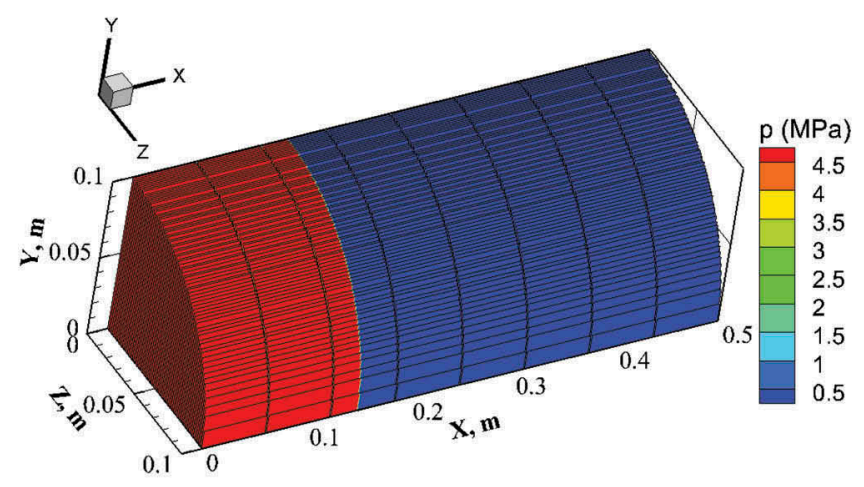

(b)

Figure 3. Transverse cross-section of the computational domain and initial pressure contour of partial domain.

In addition, the boundaries at the $X O Y$ and the $X O Z$ planes are processed by the periodic boundary method, namely, the boundary conditions at the two planes are correspondingly equal. Figure 3(b) shows the initial pressure contour for $0.5 \mathrm{~m}$ long part of the computational domain, the ignition region is $0.15 \mathrm{~m}$ long at the left side of the tube. Considering that the present study focuses on the steady detonation propagation whose parameters are not affected by the ignition source (Veyssiere, Khasainov, and Briand 2008), the ignition conditions are not unique. This simulation uses a strong ignition source, the $\mathrm{N}_{2}$ with high pressure and high velocity is filled in the ignition region and its initial parameters are $\rho_{1}=5 \mathrm{~kg} / \mathrm{m}^{3}, T_{1}=2980 \mathrm{~K}, u_{x}=850 \mathrm{~m} / \mathrm{s}, u_{y}=u_{z}=0$. The right blue region is the partial domain of the Al/air mixtures, and the initial parameters are consistent with the experimental values (Li 2017): $\rho_{1}=1.69 \mathrm{~kg} / \mathrm{m}^{3}, \sigma_{2}=405 \mathrm{~g} / \mathrm{m}^{3}, T_{1}=T_{2}=298 \mathrm{~K},|\mathrm{u}|=0,|\mathrm{v}|=0$.

Figure 4 shows the calculated pressure histories of the 14 monitoring points on the tube wall, it can be observed that the peak pressure of the detonation wave increases slowly before the $2 \mathrm{~m}$ location. The explanation is that the pressure of the detonation wave at that time is relatively lower, and the gas temperature is relatively lower too, which results that the Al particles heating is slower and it prolongs their ignition time; thus, the energy release is relative later. With the increase of the

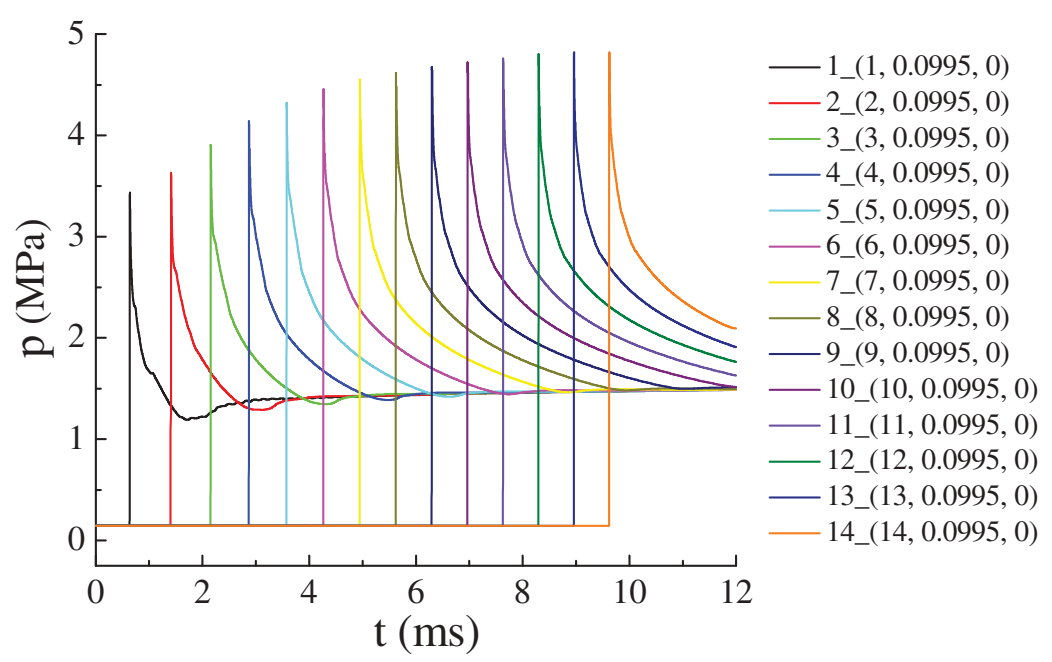

Figure 4. Pressure histories at different locations for the detonation of $\mathrm{Al} /$ air mixtures. 
leading shock wave pressure, the $\mathrm{Al}$ particles can be ignited and release energy more quickly, which leads the detonation wave pressure to increase more quickly. Finally, it develops into a steady propagating detonation wave at about the $12 \mathrm{~m}$ location, after which, the peak pressure of the detonation wave keeps constant with $4.82 \mathrm{MPa}$.

Figure 5 displays the instantaneous distributions at $t=9.07 \mathrm{~ms}$ of the gas pressure, gas temperature, gas density, gas velocity in the $X$ direction, volume fraction of $\mathrm{Al}$ particles and $\mathrm{Al}$ particles velocity in the $X$ direction for partial computational domain, where the steady detonation wave propagates at that time. One can see that, under the action of the leading shock wave, the gas is rapidly compressed to be with high pressure. Both the gas and the $\mathrm{Al}$ particles are accelerated; hence, the Al particles aggregate and increase the local concentration of them. There is an induction time for the $\mathrm{Al}$ particles ignition, and they will not release energy instantly when the shock front passes. As a result, the temperature of the gas which follows the shock front is relatively lower than that of the gas which is far behind the shock front, as shown in the gas temperature contour. Due to the tube wall friction, the gradients in the radial direction for these physical quantities can be observed, particularly for the velocities.

The calculated velocity $D$ and peak pressure $p_{\max }$ for the steady detonation wave are listed in Table 2, they agree quite well with the experimental values: $1535 \mathrm{~m} / \mathrm{s}$ and $4.8 \mathrm{MPa}$ (Li 2017), with relative errors $1.4 \%$ and $0.4 \%$, respectively, which demonstrate the improved reaction model for $\mathrm{Al}$ particles. Furthermore, the Chapman-Jouguet (CJ) parameters for the two-phase detonation wave are also obtained, the condition $D=u_{\mathrm{CJ}}+c_{\mathrm{CJ}}$, in which $u_{\mathrm{CJ}}$ and $c_{\mathrm{CJ}}$ are the gas velocity and the sound
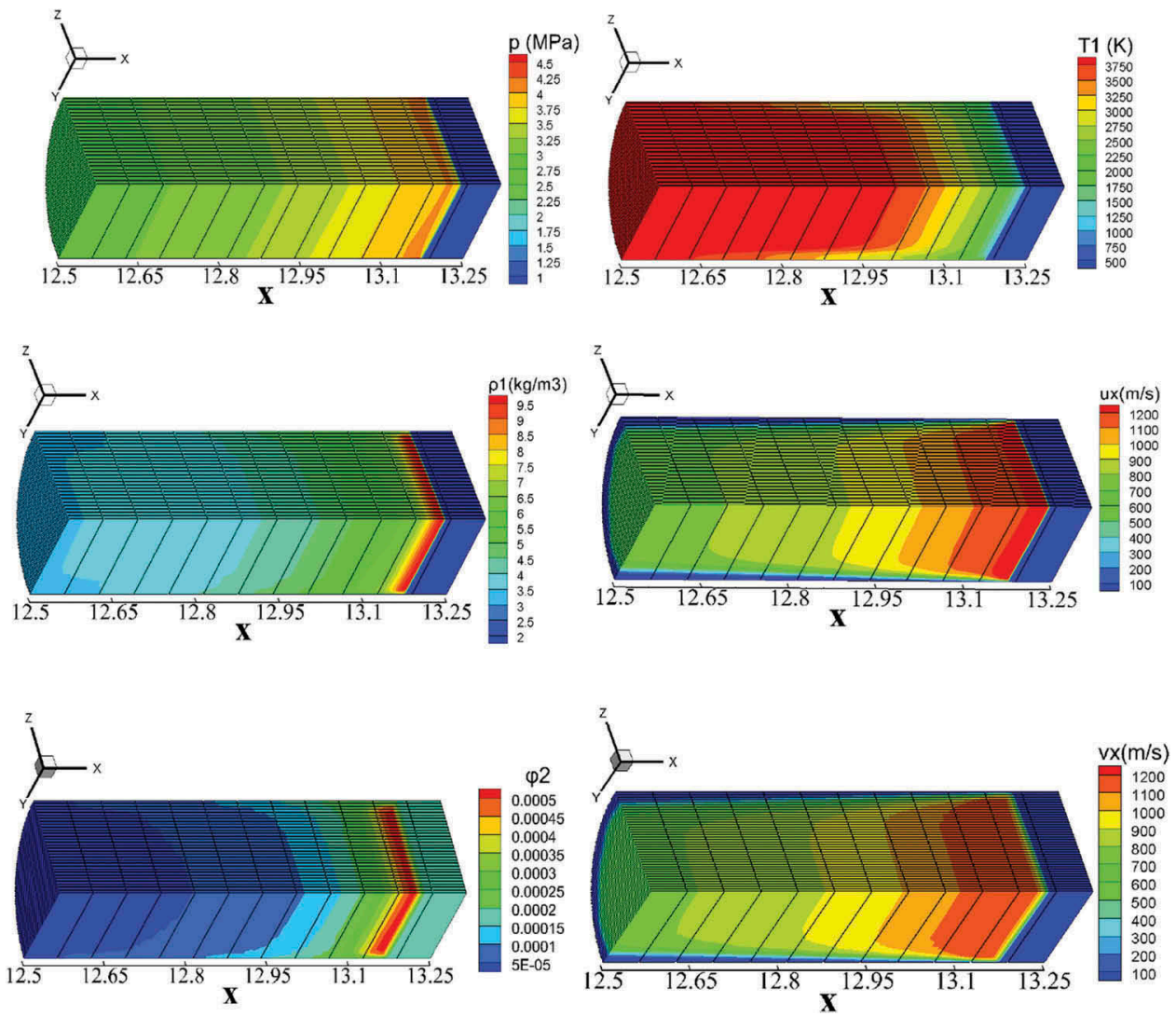

Figure 5. Distributions of gas pressure $p$, gas temperature $T_{1}$, gas density $\rho_{1}$, gas velocity in the $X$ direction $u_{x}$, volume fraction of Al particles $\varphi_{2}$, and Al particles velocity in the $X$ direction $v_{x}$ around the detonation wave for Al/air mixtures at $t=9.07 \mathrm{~ms}$. 
Table 2. Parameters of the steady propagating detonation wave for $\mathrm{Al} /$ air mixtures.

\begin{tabular}{lccccccc}
\hline Parameters & $D(\mathrm{~m} / \mathrm{s})$ & $p_{\max }(\mathrm{MPa})$ & $p_{\mathrm{CJ}}(\mathrm{MPa})$ & $\rho_{\mathrm{CJ}}\left(\mathrm{kg} / \mathrm{m}^{3}\right)$ & $u_{\mathrm{CJ}}(\mathrm{m} / \mathrm{s})$ & $T_{\mathrm{CJ}}(\mathrm{K})$ & $L_{\mathrm{CJ}}(\mathrm{m})$ \\
\hline Simulation results & 1513 & 4.82 & 2.13 & 2.59 & 436 & 3921 & 2.49 \\
\hline
\end{tabular}

${ }^{*} L_{\mathrm{C} \text { : }}$ the distance between the $\mathrm{CJ}$ plane and the detonation wavefront.

speed in the gas, respectively, is satisfied at the CJ plane. According to the simulation results, the CJ plane is $2.49 \mathrm{~m}$ away from the shock front, and the volume fraction of the Al particles $\varphi_{2}$ at the CJ plane still remains $1.2 \%$ of the initial value, this suggests that the reaction zone of the two-phase detonation is longer than that of the gas-phase detonation.

Figure 6 shows the distribution profiles of the two-phase velocities in the $X$ direction, gas temperature and concentrations of the gas species and the Al particles at the detonation tube axis. It is revealed that after the detonation wave passes, the gas velocity rises rapidly, and then the $\mathrm{Al}$ particles velocity rises under the drag force of the air. Due to the large inertia of the solid phase, the $\mathrm{Al}$ particles velocity declines more slowly, and it is even greater than the gas velocity in the space that is far behind the shock front.

The gas temperature rises under the actions of the leading shock wave and the Al particles combustion, it is worthy to be noted that the gas temperature will not keep rising by the energy release of the $\mathrm{Al}$ combustion, but is limited at about $4000 \mathrm{~K}$, this is the result of the endothermic decomposition reaction of $\mathrm{Al}_{2} \mathrm{O}_{3}$ which is introduced into the reaction model for $\mathrm{Al}$ particles in the present study, and this is in accordance with the experimental phenomenon (Glassman 1993). Besides, one can see that the gas temperature decreases slightly with the distance away from the shock front increases, the reason is that the boiling temperature of $\mathrm{Al}_{2} \mathrm{O}_{3}$, which determines whether the endothermic reverse reaction occurs or not and limits the maximum gas temperature, decreases with the pressure decreases based on the Clapeyron equation (Shen and Tong 2007).

Similarly, the concentrations of the $\mathrm{Al}$ particles and the gas components rise instantly once the shock front passes, then the $\mathrm{Al}$ particles and the $\mathrm{O}_{2}$ component are consumed quickly by the reaction. According to the simulation results, the concentrations of the $\mathrm{Al}$ particles and the $\mathrm{O}_{2}$ at the 12.5 m location remain $19 \%$ and $45 \%$ of their initial values, respectively, at $t=9.07 \mathrm{~ms}$.

\section{Improvement of the New Model}

For comparison, 3D numerical simulation for the Al/air mixtures detonation (case same to that in section 4.1) has been performed by the previous model without the reverse decomposition reaction. The simulation results by the two models are analyzed as below.

Figure 7 shows the comparison of their simulated results for the distributions of gas temperature and gas pressure around the steady detonation wave at the same time. It can be observed that the simulated gas temperature of the flow field behind the detonation wave by the previous model is up to about $4700 \mathrm{~K}$, which is significantly higher than the boiling temperature of $\mathrm{Al}_{2} \mathrm{O}_{3}$. Considering
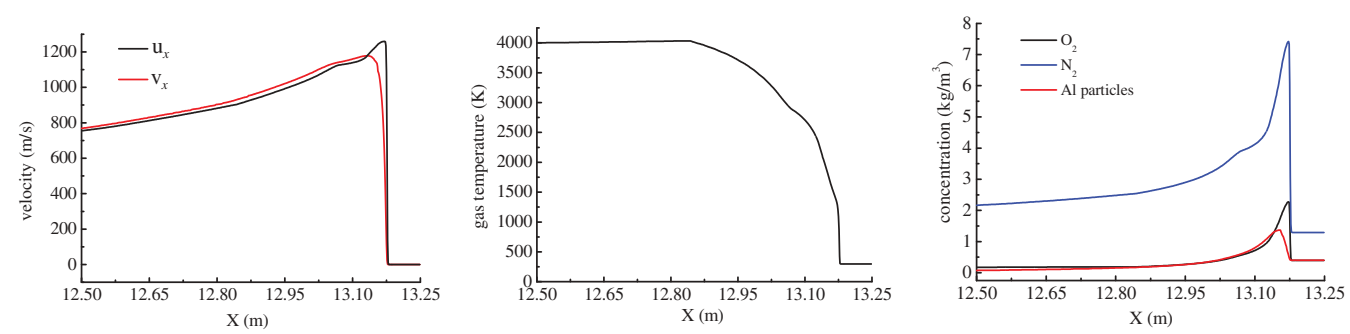

Figure 6. Longitudinal distributions of two-phase velocities in the $X$ direction, gas temperature, concentrations of gas species and Al particles at the tube axis at $t=9.07 \mathrm{~ms}$. 

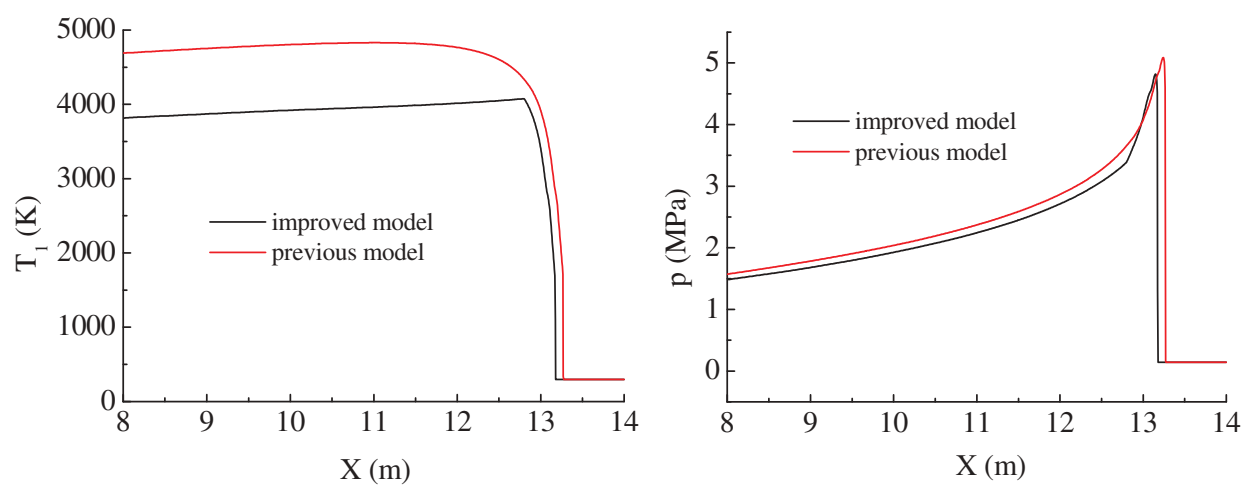

Figure 7. Comparison of distributions of gas temperature $T_{1}$ and gas pressure $p$ around the steady detonation wave by two models.

that $\mathrm{Al}_{2} \mathrm{O}_{3}$ does not exist in gaseous state, it is reasonable and necessary to include the decomposition reaction of $\mathrm{Al}_{2} \mathrm{O}_{3}$ in the reaction model. Besides, one can also see that the detonation pressure and detonation velocity simulated by the previous model are slightly greater than that of the improved reaction model.

Based on the above analysis, the improved model can accurately simulate the flow field and reflect the existing decomposition reaction of $\mathrm{Al}_{2} \mathrm{O}_{3}$ for $\mathrm{Al}$ suspensions detonation.

\section{Al/ $\mathrm{O}_{2}$ Mixtures Detonation}

The detonation experiment of $\mathrm{Al}$ particles/pure oxygen mixtures conducted by Dr. Sturtzer et al. (Sturtzer 2014) is considered. It was carried out in a self-made corner, Figure 8 shows the configuration of the experiment. In the initial moment, the $\mathrm{Al} / \mathrm{O}_{2}$ mixtures were filled in the cuboid plastic package with a size of $2 \mathrm{~m} \times 2.2 \mathrm{~m} \times 2.2 \mathrm{~m}$. The flake Al particles with an average diameter of $30 \mu \mathrm{m}$ were used and their concentration is $1.86 \mathrm{~kg} / \mathrm{m}^{3}$. The ignition source is $250 \mathrm{~g}$ C4 explosive in the corner, and two sets of sensors have recorded the pressure histories at different locations.

A 3D computational model with a size of $2.4 \mathrm{~m} \times 2.4 \mathrm{~m} \times 2.4 \mathrm{~m}$ is built to perform the simulation, Figure 9 shows the initial distribution of $\mathrm{Al}$ particles for the partial computational domain. The ignition region is $1 / 8$ sphere with a radius of $0.2 \mathrm{~m}$ at the corner, and the ignition source is simplified as N2 whose mass and energy are equal to that of the $250 \mathrm{~g} \mathrm{C} 4$ explosive. In order to ensure spherical flow, the velocity of the ignition source N2 is radial direction outward, and its initial parameters are: $\rho_{1}=59.7 \mathrm{~kg} / \mathrm{m}^{3}, T_{1}=2000 \mathrm{~K},|\mathbf{u}|=2858 \mathrm{~m} / \mathrm{s}$ (they are set to conform to the $\mathrm{C} 4$ explosion as far as possible but not unique). The initial parameters of the $\mathrm{Al} / \mathrm{O}_{2}$ mixtures are consistent with the experimental values: $\rho_{1}=1.28 \mathrm{~kg} / \mathrm{m}^{3}, \sigma_{2}=1.86 \mathrm{~kg} / \mathrm{m}^{3}, T_{1}=T_{2}=298 \mathrm{~K}$, | $\mathbf{u}|=0,| \mathbf{v} \mid=0$. Similar to Dr. Sturtzer's simulation work, the flake Al particle is equivalent to the spherical particle with a diameter of $8.6 \mu \mathrm{m}$, and based on the size of the flake particle, the surface area ratio $\beta$ (Equation (14) in the paper) is 6.28 . The boundary conditions at the $X O Y, Y O Z$, and $X O Z$ planes correspond to the rigid wall, and the boundary conditions at the other three planes are flow out.

Considering the large computational domain, the mesh intervals in the $X, Y$, and $Z$ directions are all $5 \mathrm{~mm}$, namely, 481 grid nodes are used in each direction. The computational domain is averagely divided into six parts in all the three directions; thus, it is divided into 216 cuboid computational domains with a size of $0.4 \mathrm{~m} \times 0.4 \mathrm{~m} \times 0.4 \mathrm{~m}$, and the numerical simulation is performed on 216 processors with a parallelization based on the MPI technique. There are 13 monitoring points on the computational domain's diagonal line which crosses the corner point recording the pressure histories. 


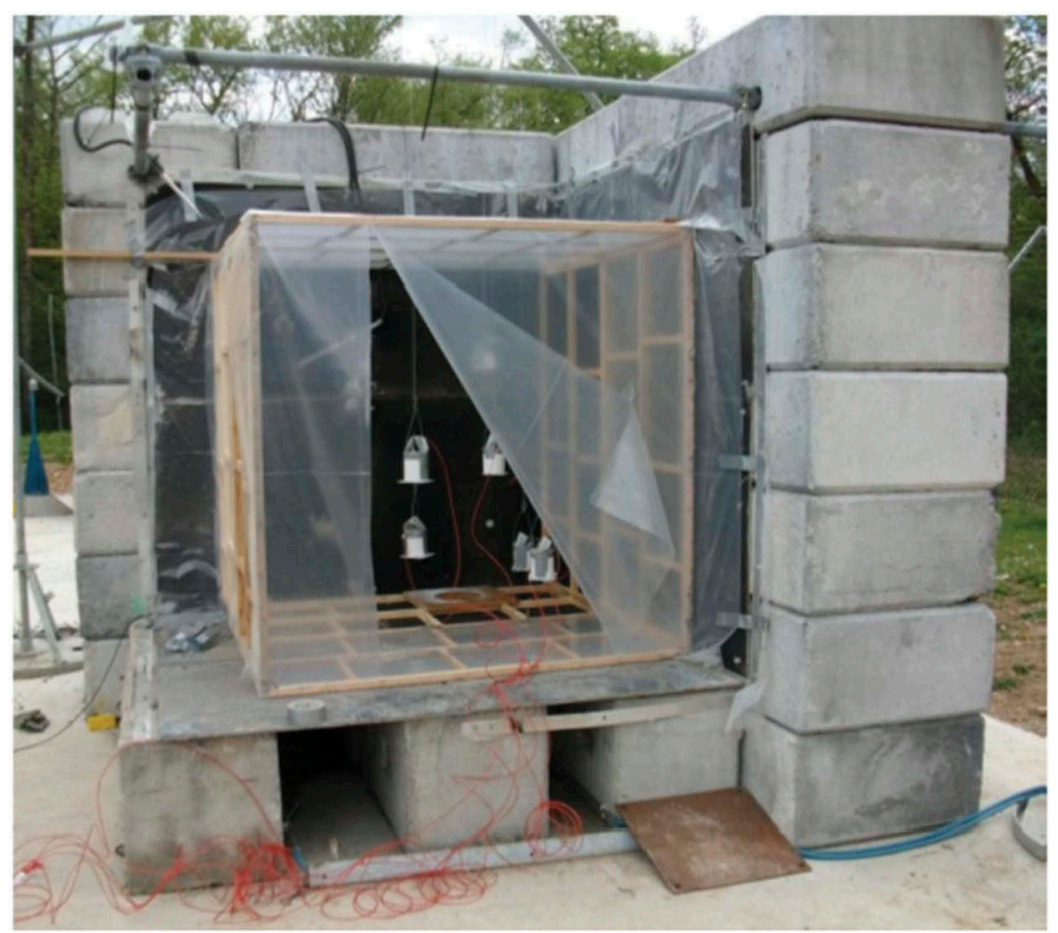

Figure 8. Configuration of the $\mathrm{Al} / \mathrm{O}_{2}$ mixtures detonation experiment.

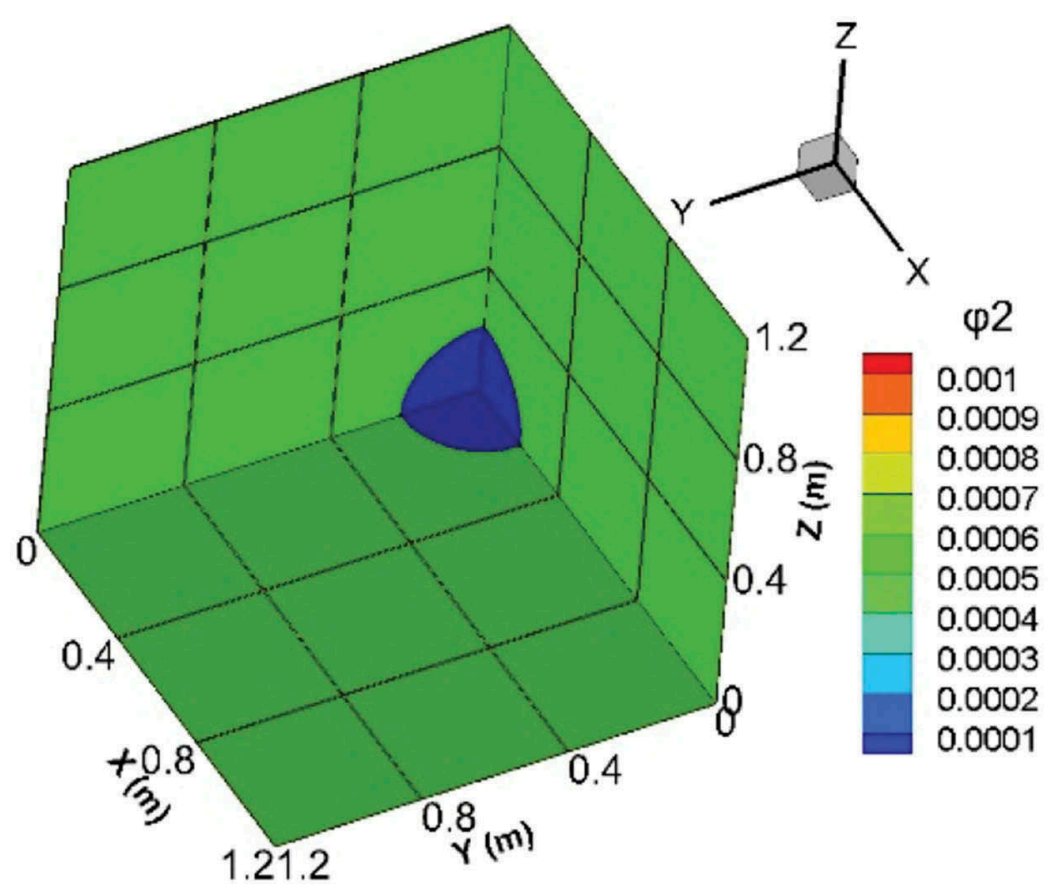

Figure 9. Initial distribution of Al particles for partial computational domain. 
Figure 10 shows the instantaneous distributions at $t=0.82 \mathrm{~ms}$ of gas pressure $p$, gas temperature $T_{1}$, gas density $\rho_{1}$, and volume fraction of $\mathrm{Al}$ particles $\varphi_{2}$ for partial computational domain with a size of $1.6 \mathrm{~m} \times 1.6 \mathrm{~m} \times 1.6 \mathrm{~m}$. It can be observed that the spherical detonation wave propagates outward, and its peak pressure is about $3.7 \mathrm{MPa}$ at that time. Due to the flow out of the gas, the gas density near the corner decreases, and it leads to the low pressure of this area. Under the action of the leading shock wave, the $\mathrm{Al}$ particles aggregate and begin to combust, resulting in a high temperature of the flow field. The Al particles near the corner almost burn out at that time; thus, the temperature of the gas near the corner is relatively lower than that of the gas which follows the shock front, as shown in the gas temperature contour.

Figure 11 shows the calculated pressure histories of the 13 monitoring points on the computational domain's diagonal line. In the earlier time, the peak pressure of the shock wave generated by the ignition source decreases with the increase of the distance, when it decays to 3.1 MPa at about $1.73 \mathrm{~m}$, the energy released by the $\mathrm{Al}$ combustion is able to make it not decay anymore. After that, the detonation wave pressure even increases slowly due to $\mathrm{Al}$ combustion. In fact, the two-phase detonation has not yet developed into a stable stage within the short distance.

The detonation velocities are calculated based on the detonation wave arrival time at different locations. Figure 12 shows the comparison of the simulated and the experimental detonation velocities. Considering that the ignition source used in the computational model is not exactly
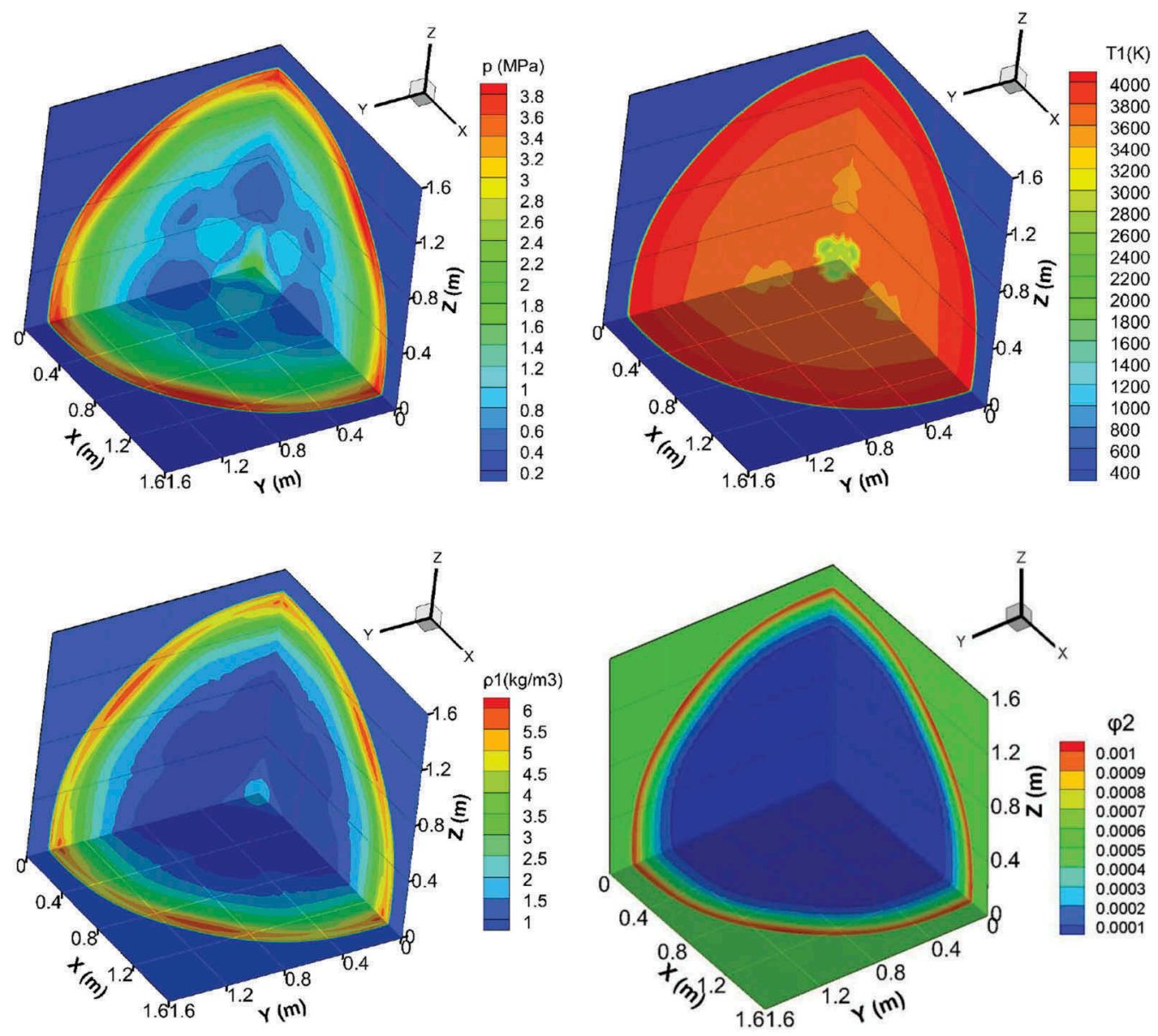

Figure 10. Distributions of gas pressure $p$, gas temperature $T_{1}$, gas density $\rho_{1}$, and volume fraction of Al particles $\varphi_{2}$ for Al/ $\mathrm{O}_{2}$ mixtures detonation at $t=0.82 \mathrm{~ms}$. 


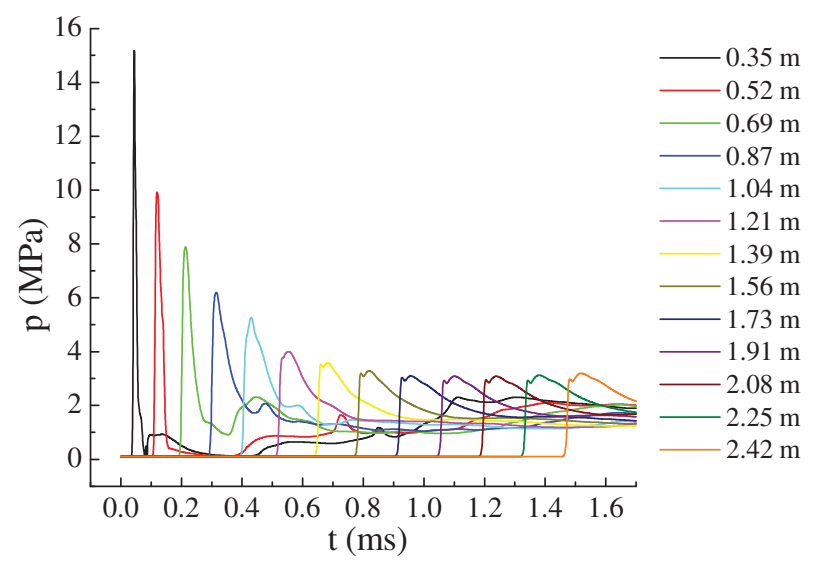

Figure 11. Pressure histories at different distances from the corner point.

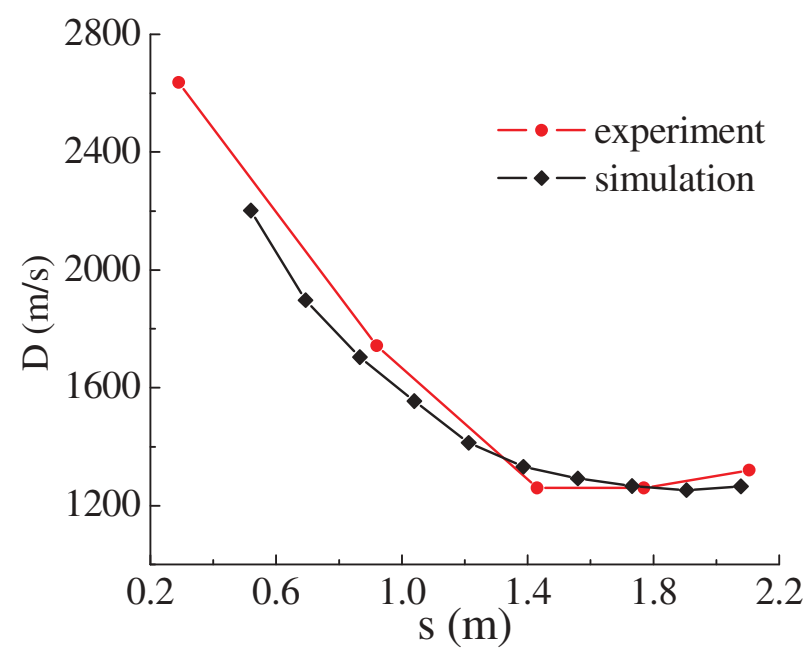

Figure 12. Comparison of simulated and experimental detonation velocities at different locations.

the same as the experimental ignition source, it is reasonable for the large relative error between the simulated and the experimental velocities at the flow field near the ignition region. While at the flow field that is more than $1 \mathrm{~m}$ away from the ignition region, the influence caused by the difference between the ignition sources becomes less, it appears that the simulated and the experimental results are almost consistent, with relative errors basically lower than $4 \%$, indicating that the improved $\mathrm{Al}$ reaction model is suitable for the simulation of the $\mathrm{Al} / \mathrm{O}_{2}$ mixtures detonation.

\section{Conclusions}

Modeling of aluminum reaction is the major difficulty in the numerical simulation for two-phase detonation of aluminum suspensions. In this study, the reaction model is improved by introducing the decomposition reaction of the product $\mathrm{Al}_{2} \mathrm{O}_{3}$, and the new model is more realistic. Afterward, it is incorporated into the numerical code to simulate the two-phase detonations for $\mathrm{Al} /$ air mixtures and $\mathrm{Al} / \mathrm{O}_{2}$ mixtures, respectively, good agreements are observed between the simulation results and 
the experimental results, which indicates that the improved reaction model for $\mathrm{Al}$ particles can simulate the two-phase detonation of $\mathrm{Al}$ suspensions in different oxidizing atmosphere.

\section{References}

Balakrishnan, K. 2014. Diffusion-and kinetics-limited combustion of an explosively dispersed aluminum particle. Journal of Propulsion and Power 30 (2):522-26. doi:10.2514/1.B35059.

Bazyn, T., H. Krier, and N. Glumac. 2007. Evidence for the transition from the diffusion-limit in aluminum particle combustion. Proceedings of the Combustion Institute 31 (2):2021-28. doi:10.1016/j.proci.2006.07.161.

Beckstead, M. W. 2005. Correlating aluminum burning times. Combustion Explosion Shock Waves 41 (5):533-46. doi:10.1007/s10573-005-0067-2.

Briand, A., B. Veyssiere, and B. A. Khasainov. 2010. Modelling of detonation cellular structure in aluminium suspensions. Shock Waves 20:521-29. doi:10.1007/s00193-010-0288-5.

Fedorov, A. V., and T. A. Khmel. 2005. Numerical simulation of formation of cellular heterogeneous detonation of aluminium particles in oxygen. Combustion Explosion Shock Waves 41 (4):435-48. doi:10.1007/s10573-005-0054-7.

Glassman, I. 1993. Combustion of metals revisited-thermo-dynamically. Proceedings of the Eastern States Section of the Combustion Institute, The Combustion Institute. 17-26. South Carolina, United States.

Glorian, J., S. Gallier, and L. Catoire. 2016. On the role of heterogeneous reactions in aluminum combustion. Combustion and Flame 168:378-92. doi:10.1016/j.combustflame.2016.01.022.

Haynes, W. M. 2014. Handbook of chemistry and physics. Florida: CRC Press.

Hong, T., and C. S. Qin. 2003. Mechanism of shock wave ignition of aluminum particle. Chinese Journal of Explosion and Shock Waves 23 (4):295-99.

Kwon, Y. S., A. A. Gromov, A. P. Ilyin, E. M. Popenko, and G. H. Rim. 2003. The mechanism of combustion of superfine aluminum powders. Combustion and Flame 133 (4):385-91. doi:10.1016/S0010-2180(03)00024-5.

Levitas, V. I., M. L. Pantoya, G. Chauhan, and I. Rivero. 2009. Effect of the alumina shell on the melting temperature depression for aluminum nanoparticles. The Journal of Physical Chemistry C 113 (32):14088-96. doi:10.1021/ jp902317m.

Li, S. Z. 2017. Study on deflagration to detonation transition process of gas/solid/liquid multiphase fuel mixtures. PhD diss., Beijing Institute of Technology

Liu, X. L., and Q. Zhang. 2015. Influence of turbulent flow on the explosion parameters of micro- and nano-aluminum powder-air mixtures. Journal of Hazardous Materials 299:603-17. doi:10.1016/j.jhazmat.2015.07.068.

Nigmatulin, R. I. 1970. Prikl. Matemat. Mekh. 34:1097-112.

Price, E. W. 1984. Combustion of metalized propellants. Progress in Astronautics and Aeronautics: Fundamentals of Solid-Propellant Combustion 90:479-513.

Shen, W. D., and J. G. Tong. 2007. Engineering thermodynamics. Beijing: Higher Education Press.

Steinberg, T. A., D. B. Wilson, and F. Benz. 1992. The combustion phase of burning particle. Combustion and Flame 91:200-08. doi:10.1016/0010-2180(92)90100-4.

Sturtzer, C. A. 2014. Study on shock dispersion mechanisms and cloud combustion regimes for aluminum particles. PhD diss., National Higher School of Mechanics and Aeronautics (ENSMA), France

Tanguay, V., S. Goroshin, A. J. Higgins, and F. Zhang. 2009. Aluminum particle combustion in high-speed detonation products. Combustion Science and Technology 181 (4):670-93. doi:10.1080/00102200802643430.

Toro, E. F. 2009. Riemann solvers and numerical methods for fluid dynamics. Dordrecht Heidelberg London New York: Springer. doi:10.1007/978-3-540-49834-6.

Veyssiere, B., B. A. Khasainov, and A. Briand. 2008. Investigation of detonation initiation in aluminium suspensions. Shock Waves 18 (4):307-15. doi:10.1007/s00193-008-0136-z.

Zhang, F., K. Gerrard, and R. C. Ripley. 2009. Reaction mechanism of aluminum- particle-air detonation. Journal of Propulsion and Power 25 (4):845-58. doi:10.2514/1.41707. 